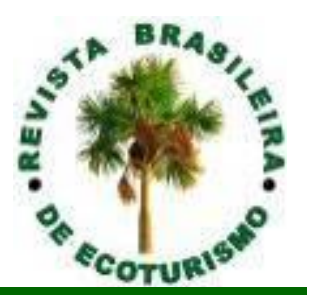

\title{
Divulgação da RPPN Estadual MO'Ã como estratégia para a conservação
}

\section{Disclosure of the State RPPN MO'Ã as a strategy for conservation}

\author{
Letícia Ramires Corrêa, Tuane Telles Rodrigues
}

\begin{abstract}
RESUMO: A reaproximação do ser humano com a natureza, sempre foi o grande desafio para os educares ambientais. $\mathrm{Na}$ busca pela sensibilização a unidade de conservação vem ao encontro deste propósito, oferecendo espaços que possibilitem o contato direto com a natureza. Este trabalho visa discutir a experiência de divulgação da RPPN Estadual MO'Ã a partir de palestras proferidas nas escolas e em eventos científicos. Esta proposta foi construída a partir da solicitação das as escolas e de organizações de eventos, afim de divulgar o Patrimônio Natural e sensibilizar os ouvientes para as questões ambientais, a partir de eventos promovidos pelas mesmas. Para isso foram realizadas palestras abordando temas a partir das demandas dos eventos, tendo como foco principal a divulgação da RPPN Estadual MO'Ã. Nesse sentido foram realizadas seis palestras, duas em Itaara e duas em Santa Maria (Brasil) e duas em Guimarães (Portugal), abrangendo um público de quinhentos (500) ouvintes. Tais ações foram relevantes para divulgar o Patrimônio Natural da RPPN, afim de sensibilizar os ouvintes a partir do exemplo da Fundação MO'Ã, como uma Organização Não-Governamental (ONG) que promove a conservação do meio ambiente da região central do Rio Grande do Sul.
\end{abstract}

PALAVRAS CHAVE: Educação Ambiental; Interpretação Ambiental; Sensibilização; RPPN Estadual MO'Ã; Itaara/RS.

ABSTRACT: The rapprochement of the human being with nature has always been the great challenge for environmental educators. In the quest for awareness, the conservation unit meets this purpose, offering spaces that allow direct contact with nature. This paper aims at discussing the experience of dissemination of the RPPN State MO'Ã from lectures given in schools and scientific events. This proposal was built on the request of schools and event organizations in order to disseminate Natural Heritage and raise awareness of environmental issues, based on events promoted by them. For this, lectures were given on subjects from the demands of the events, with the main focus being the dissemination of RPPN Estadual MO'Ã. In this sense, six lectures were held, two in Itaara and two in Santa Maria (Brazil) and two in Guimarães (Portugal), covering an audience of five hundred (500) listeners. These actions were relevant to publicizing the Natural Patrimony of the RPPN, in order to sensitize the listeners from the example of the MO'Ã Foundation, as a Non-Governmental Organization (NGO) that promotes the conservation of the environment of the central region of Rio Grande do Sul (Brazil).

KEYWORDS: Environmental Education; Environmental Interpretation; Awareness; State RPPN MO'Ã; Itaara (RS, Brazil). 


\section{Introdução}

Direcionar para a mudança de atitude e do comportamento dos seres humanos dependem basicamente da instrução e sensibilização dos indivíduos, e é na educação que se encontra uma das principais possibilidades para o problema ser superado, para despertar uma consciência geral na população da necessidade e importância da conservação do ecossistema terrestre (SICK, 1997).

Tal processo de educação, acontece durante o estabelecimento de relações no convívio social, tanto na escola quanto em casa, nas ruas da cidade ou em espaços naturais, como Unidades de Conservação (UCs). Pois este é o momento em que o indivíduo interage com o meio fazendo de suas relações, uma construção de uma consciência a partir das experiências.

Se possibilita uma reaproximação das comunidades com a natureza através da criação de espaços protegidos (Unidades de Conservação) que permitam a (re) interpretação ambiental, a fim de redescobrir o sentido da natureza na relação com o humano, divulgando a conservação, preservando a vida e resgatando a ética interespecífica antes perdida (DOUROJEANNI; PÁDUA, 2007).

A RPPN Estadual MO'Ã como a única RPPN instituída na região central do Rio Grande do Sul, sendo zona núcleo da Reserva da Biosfera da Mata Atlantica e compondo o Corredor Ecológico da Quarta Colonia, tem um papel fundamental junto a comunidade, no sentido de sensibilização para a conservação. Para isso a Fundação MO'Ã, como um ONG que promove a conservação do meio ambiente e proprietária da RPPN, realiza palestras junto as escolas com o objetivo de divulgar o Patrimônio Natural da RPPN e sensibilizar para conservação da natureza.

Este trabalho visa discutir as experiências em relação a divulgação da RPPN a partir de palestras proferidas em escolas e eventos acadêmicos, na região central do Rio Grande do Sul e em Portugal, como iniciativa para a construção de um vínculo entre comunidade escolar, instituições de ensino e entidades voltadas a preservação e/ou conservação da natureza e esta Unidade de Conservação.

\section{A Reserva Particular do Patrimônio Natural Estadual MO'Ã: a história até aqui}

Com uma abordagem preservacionista, a criação do Parque Nacional de Yellowstone, em 1872, traz um modelo para a proteção da natureza que foi exportado para o mundo todo, que para muitos países ainda vigora (BENSUSAN, 2006). Este modelo tem por objetivo preservar "paisagens virgens", o que causou e causa muitos conflitos pela desapropriação de terras (DIEGUES, 2002).

No contexto do Brasil, tem-se nas Unidades de Conservação (UCs) uma estratégia para associar as necessidades tanto preservacionistas, como as UCs de proteção integral, quanto conservacionistas, como as UCs de uso sustentável. Essas tipologias são consagradas com o advento de uma política específica no país no ano 2000: o Sistema Nacional de Unidades de Conservação (SNUC), o qual se apresenta como um importante instrumento legal, pois, estabelece critérios e normas para a criação, implantação e gestão de UCs. Além disso, no SNUC encontram-se os entendimentos de conceitos relacionados às UCs assim como, seus objetivos, tipos de categorias e as esferas de gestão. 
O conceito de Unidade de Conservação é discutido e muitas vezes confundido com o conceito de áreas protegidas. Bensusan (2006) salienta que este conceito de UC não apresenta correspondência com termos de outros idiomas e que por alguns autores é considerado como subconjunto das áreas protegidas. Porém segundo (BRASIL, 2000), define-se UC como:

espaço territorial e seus recursos ambientais, incluindo as águas jurisdicionais, com características naturais relevantes, legalmente instituído pelo Poder Público, com objetivos de conservação e limites definidos, sob regime especial de administração, ao qual se aplicam garantias adequadas de proteção.

As UCs dividem-se em dois grupos: as Unidades de Proteção Integral e as Unidades de Uso Sustentável. As Unidades de Proteção Integral têm por objetivo a preservação da natureza e, por isso, neste grupo só se pode utilizar os recursos naturais aí existentes de forma indireta. Já as Unidades de Uso Sustentável têm por objetivo relacionar a conservação da natureza com o uso sustentável de parte dos recursos naturais aí existentes permitindo, portanto, o uso direto de determinadas áreas das unidades. É este último grupo que, portanto, se permite pensar em possibilidades de desenvolvimento através das UCs federais.

No grupo de Uso Sustentável há uma categoria de manejo chamada de Reserva Particular do Patrimônio Natural (RPPN). A RPPN é uma categoria criada pela iniciativa do proprietário e sua gestão é partilhada entre o poder público e o proprietário. Elas têm como principal característica a conservação da diversidade biológica, garantindo ao proprietário a titularidade do imóvel (BRASIL, 2000). Outra característica relevante nesta categoria é o caráter de perpetuidade, ou seja, ela pode ser vendida, doada ou heradada mas não poderá deixar de ser uma RPPN.

Em alguns Sistemas Estaduais de Unidades de Conservação (SEUCs), como o do Rio Grande do Sul, esta categoria encontra-se no grupo de proteção integral. Um exemplo disso é a RPPN Estadual MO'Ã, área desta pesquisa. Que foi instituída em nível estadual com isso se enquadra na categoria de uso indireto no grupo de proteção integral definindo as RPPNs como "áreas particulares, com objetivo de preservação do ambiente natural, gravada com perpetuidade, sem implicar em desapropriações, sob a fiscalização governamental' (SEUC, 1998).

$O$ processo de criação de uma RPPN é assumido inteiramente pelo proprietário. No caso da RPPN Estadual MO'Ã, os atores principais dessa jornada por sua instituição são o casal Rainer Oscar Müller e Eleonora Diefenbach (casal de instituidores e mantenedores da Fundação MO'Ã). Que em 2007 conheceram e adquiriram uma área na comunidade conhecida como Rincão dos Minellos em Itaara, por ser uma área com características naturais relevantes, foi doada para Fundação MO'Ã, (CHAMI; DEON; SILVA, 2014).

Esta área está localizada na região central do estado do Rio Grande do Sul, no município de Itaara, situa-se ao sul do território deste município, possuindo cerca de 21 há (Figura 1). 


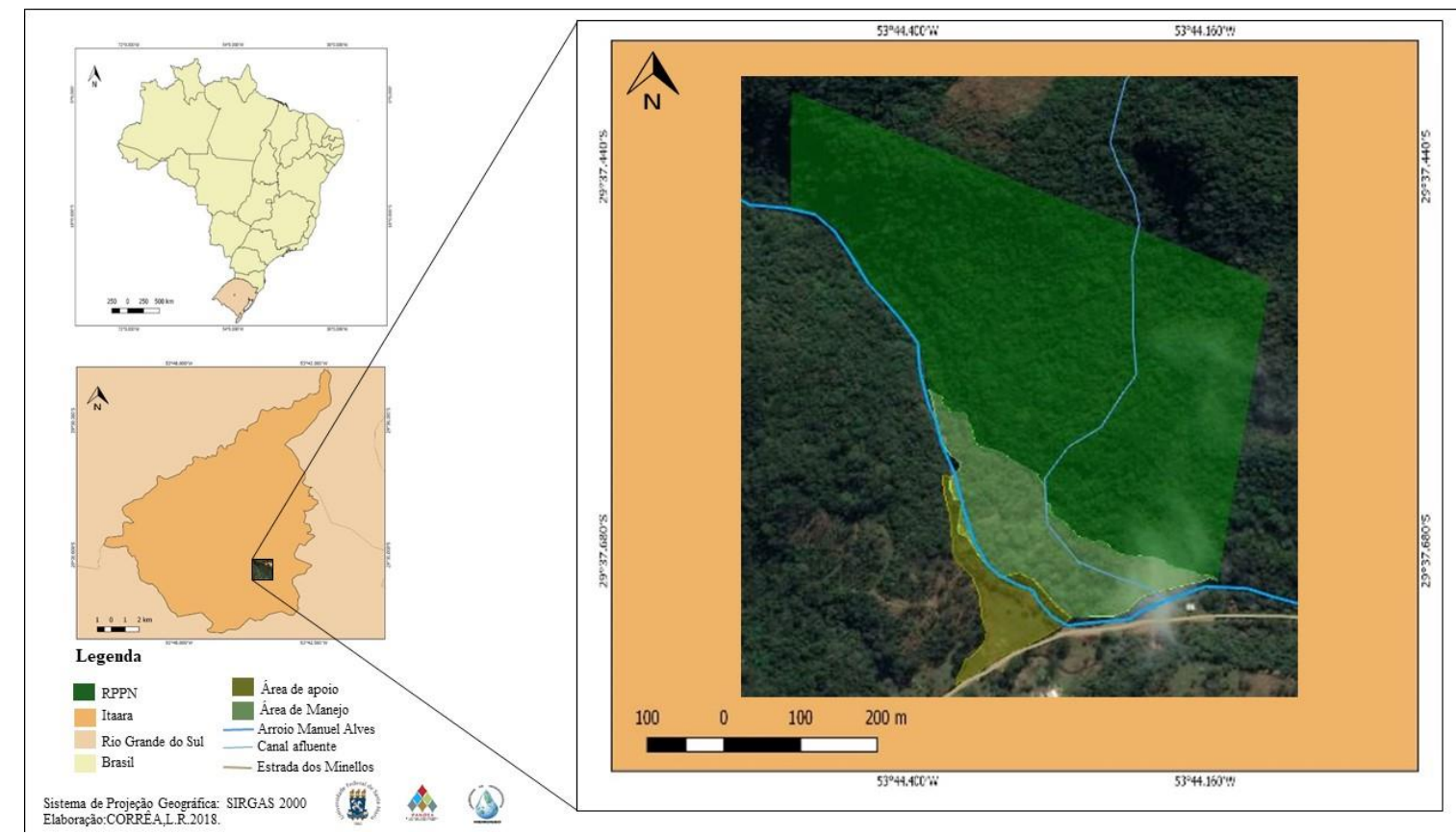

Figura 1: Mapa de localização da RPPN Estadual MO'Ã

Figure 1 - Location map of the State RPPN MO'Ã

Fonte: Autores, 2018.

Source: Authors, 2018.

Sua área compõe a zona núcleo da Reserva da Biosfera da Mata Atlântica ${ }^{1}$, reconhecida como um patrimônio mundial pela UNESCO (Organização das Nações Unidas para a Educação, a Ciência e a Cultura).

Inicia-se o processo de criação da então única RPPN da região central do estado, considerando seus atributos naturais, como remanescentes de vegetação nativa, a o Arroio Manuel Alves limite natural da propriedade e mais um canal que passa dentro da propriedade, onde segundo os proprietários a presença da água foi um elemento importante para aquisição da área, assim como ela estar localizada dentro da Reserva da Biosfera da Mata Atlântica.

Este processo começa com o georreferenciamento da área para a implantação da RPPN. Onde houve dificuldades em relação a definição dos limites da área, pois o georreferenciamento realizado pelo antigo proprietário estava incompleto, dificultando o reconhecimento do limite a oeste. Foi realizado uma atualização do georreferenciamento, definindo como limite o Arroio Manuel Alves.

Com isso a Fundação MO'Ã pode fazer o cercamento da área para evitar a entrada do gado das propriedades vizinhas e a construção da ponte de acesso.

Em março de 2008, a área da RPPN estava na trajetória de uma linha de alta-tensão, projetada para transmitir energia do município de Dona Francisca até o município de Santa Maria. A partir do convênio de cooperação técnico científica entre a Fundação MO'Ã e a Universidade Federal de Santa Maria, mapeamentos foram realizados por estagiários da Fundação MO'Ã, onde se constatou que cerca de 1 ha de mata nativa seria derrubada, devido a faixa de servidão. Foram 
realizados contatos com a empresa responsável pela obra, e a linha de transmissão de energia elétrica foi desviada (THOMAS et al,2010).

Avançou-se no processo de criação com a realização de um diagnóstico ambiental da área, em 2008 e 2009, onde foram mapeados os cursos d'águas presentes na propriedade, e produção de mapas de declividade, hipsométrico, de cobertura vegetal e de Zoneamento Ambiental.

De certa forma a realização do diagnóstico ambiental da propriedade da Fundação MO'Ã visou à implantação da RPPN e trouxe a discussão das áreas protegidas para a esfera do Poder Público Municipal na região central do Rio Grande do Sul (KORMANN et al., 2010).

A partir de então buscou-se instituir a RPPN através de um Projeto de Lei Municipal de criação de RPPNs em Itaara. Porém o processo tornou-se longo, com a troca de mandato dos prefeitos, e levou a Fundação MO'Ã a buscar a criação da RPPN em nível estadual (KORMANN et al., 2010).

Diante do exposto, em 15 de junho de 2015, a Reserva Particular do Patrimônio Natural Estadual MO'Ã foi instituída, tendo por finalidade promover a proteção dos recursos ambientais e a conservação da diversidade biológica de acordo com a Portaria no 80, de 15 de junho de 2015 (RIO GRANDE DO SUL, 2015), com uma área de 21,0156 hectares, de flora, fauna, biota, hidrografia. Além disso, tal reserva tem um potencial relevante pela sua posição geográfica, na região central do Rio Grande do Sul, o objetivo da Fundação MO'Ã é que a RPPN sirva como um polo irradiador de práticas sustentáveis para o seu entorno.

Com isso, destaca-se que a Fundação MO'Ã vem desenvolvendo ações e pesquisas nesta área de abrangência, principalmente em Santa Maria e Itaara, há alguns anos, fortalecendo as relações entre sociedade e natureza, com a referente pesquisa, que se faz pioneira na propriedade, busca-se intensificar essas relações através da IA.

Destacando-se pelas trabalhos realizados por alunos da Universidade Federal de Santa Maria (UFSM) e Universidade Federal do Pampa (UNIPAMPA) através do Termo de Cooperação Técnica-científica entre Fundação MO'Ã e Universidades, onde já foram executados trabalhos na área como: Mapeamento Geoambiental, Diagnóstico ambiental, Zoneamento ambiental, Distribuição da precipitação pluviométrica, Cobertura pedológica em topossequência, Levantamento da Mastofauna, Levantamento Florístico, Proposta de Trilha Interpretativa, levantamento de exóticas invasoras, entre outros (FUNDAÇÃO MO'Ã, 2017). Desta forma valorizando a área da RPPN como espaço importante para pesquisa na região central do estado.

\section{RPPN Estadual MO'Ã: analise da sua paisagem}

A área da referente pesquisa está situada no Rebordo do Planalto, que é caracterizado por derrames basálticos fissurais e por possuir solos rasos em declividades acentuadas, apresenta escarpas cobertas por florestas subtropicais de grande porte (NASCIMENTO, 2009). 
A RPPN é drenada pelos canais que compõem a micro bacia Arroio Manuel Alves, que é um dos afluentes do Arroio Grande, integrante da bacia hidrográfica do rio Vacacaí-Mirim, da região hidrográfica do Guaíba. A dinâmica fluvial desta bacia hidrográfica é bem peculiar por seus canais de grande energia de transporte nas porções de maior inclinação da vertente, o que facilita a ocorrência de enxurradas em períodos chuvosos (KORMANN et al., 2009), causando o difícil acesso a propriedade, que, por sua vez utilizava de uma ponte de madeira construída pela Prefeitura Municipal de Itaara, que não resistiu as intensas chuvas e enchentes, que acabaram por destruir a ponte e deixara propriedade com dificuldades de acesso.

Estas condições são verificadas nas porções de montante do canal fluvial, onde as vertentes se apresentam mais encaixadas, situadas na parte norte da área de estudo, muito em função da declividade da área (KORMANN et al., 2010).

As regiões propícias a enxurradas ${ }^{2}$ estão localizadas nas áreas mais planas, onde a energia cinética do rio é quebrada e ele extravasa. Enquanto na porção sul, com menor declividade, há a consequente perda dessa energia de transporte, formando ilhotas de rochas com presença de matacões, que são grandes blocos rochosos, arredondados, que no caso da RPPN, são na sua maioria basaltos, formando canais entrelaçados típicos de regiões montanhosas e poços que armazenam vida aquática (KORMANN et al., 2011).

Diante da relevância da área para a conservação destaca-se que ela compõe - Corredor Ecológico da Quarta Colônia, que consiste em áreas que possuem ecossistemas florestais biologicamente prioritários e viáveis para a conservação da biodiversidade, no caso a Mata Atlântica. O corredor liga a Reserva Biológica do Ibicuí Mirim em Itaara e estende-se até o Parque Estadual da Quarta Colônia que está situado nos municípios de Agudo e Ibarama, na bacia hidrografia do Rio Jacuí (MARCUZZO, 2013; BRASIL, 2014).

No interior da área encontra-se uma paisagem atrativa que aguça os sentidos, o ar puro, o som do rio, as diferentes texturas de folhas, caules e rochas, as cores dos diferentes tons de verde e o colorido das flores, faz da RPPN Estadual MO'Ã um espaço propício à Interpretação Ambiental (CORRÊA; FIGUEIRÓ, 2016).

Diante disso, Kormann et al. (2010) refletem sobre a importância da área da RPPN ser preservada, diante dos resultados do diagnóstico de áreas prioritárias à conservação no estado do Rio Grande do Sul com remanescentes de Mata Atlântica, que desde 1993 estão tombados como Reserva da Biosfera da Mata Atlântica pelo programa "MaB"- O Homem e a Biosfera, da UNESCO.

Segundo Ferrarese (2016), na área, a vegetação mais preservada ocorre nas regiões de maior declividade, com vertentes bem inclinadas, caracterizado por encostas de rochas vulcânicas, com acúmulo de serapilheira sobre rochas, sendo predominante na paisagem.

$\mathrm{Na}$ parte de acesso à RPNN, que fica na porção campestre (FERRARESE,2016) distribuída em áreas de menor declividade e altimetria, observa-se um campo em regeneração, apresentando algumas áreas úmidas próximas aos cursos d'água.

Por ser uma área bem drenada, possui uma flora abundante segundo Ferrarese (2016), foram identificados 277 taxa vegetais (nativos do Brasil) na RPPN 
Estadual MO'Ã, havendo alguns problemas como a questão sobre plantas exóticas e seus riscos a flora nativa, como por exemplo a Uva-do-Japão (Hovenia dulcis Thunb), que tornou-se um problema na propriedade pelo seu poder de disseminação. Por ser muito doce, os animais silvestres preferem esses frutos exóticos aos nativos. A fauna dissemina milhares de sementes para o meio da mata nativa preservada e ao longo dos anos as árvores nativas vão perdendo espaço para a exótica (MAIEVES et al., 2015).

Tendo em vista a importância do levantamento florístico da referente área, destacam-se duas espécies na categoria criticamente em perigo $(\mathrm{CR})^{3}$, indicando que estão enfrentando um risco extremamente elevado de extinção na natureza, sendo elas a Araucaria angustifolia abrangida pela listagem do RS declaradas pelo Decreto no 52.109, de dezembro de 2014 e através de consultas disponíveis nos site do Centro Nacional de Conservação da Flora, que conduz a avaliação do risco de extinção das espécies nativas do Brasil e da IUCN que considera os graus de ameaça apresentados pela Red List disponíveis no site da International Union for Conservation of Nature (IUCN), que representa as gimnospermas nativas na RPPN MO'Ã, das quais são oriundas do plantio antrópico, mais recente devido a seu menor porte Ferrarese (2016) , e Oxalis subvillosa, foi observado um elevado número desta última espécie, muito em função da dificuldade de acesso, sendo que foram observadas no interior da floresta, esta é a segunda população encontrada no Rio Grande do Sul e foi abrangida apenas pela primeira lista Ferrarese (2016).

\section{Metodologia}

A realização deste trabalho adotou uma metodologia de pesquisa-ação participativa, a qual articula a produção de conhecimentos, a ação educativa e a participação dos envolvidos, isto é, produz conhecimentos sobre a realidade a ser estudada e, ao mesmo tempo, realiza um processo educativo, participativo, para o enfrentamento dessa mesma realidade (TOZONI-REIS, 2005).

Assim, a pesquisa-ação tem como ponto de partida a articulação entre a produção de conhecimentos para a conscientização dos sujeitos e a solução de problemas socialmente significativos. Diante desta metodologia que se considera relevante o envolvimento da pesquisadora com o tema e principalmente com a área de estudo a qual foi divulgada.

Tendo em vista que a pesquisadora é estagiária da Fundação MO'Ã e desenvolve trabalhos desde 2014 no âmbito de educação ambiental, junto a comunidade de Itaara, já é conhecida pela comunidade escolar que solicita junta a fundação para a realização de palestras em eventos relacionados ao meio ambiente.

Para isso a escola Municipal de Ensino Fundamental Alfredo Lenhardt realiza anualmente a Conferência do Meio Ambiente e Qualidade de Vida e Cidadania. E a fundação contribuiu com uma palestra de divulgação da RPPN e discutiu a importância dos recursos hídricos.

A escola Municipal de Ensino Fundamental Pão dos pobres Santo Antônio realiza localizada em Santa Maria/RS, organiza anualmente o Seminário de Educação Ambiental: da teoria à prática. 
Ambas as escolas receberam uma palestra de divulgação e sensibilização sobre a RPPN Estadual MO'Ã.

Utilizou-se apresentação de slides para a exibição das imagens, que foram selecionadas de acordo com a faixa etária (12 a 15 anos). Contando com alunos de 6ำ a $9^{\circ}$ ano.

$\mathrm{Na}$ Universidade do Minho em Guimarães (Portugal) utilizamos uma abordagem com histórico da Fundação e da área e sua relevância para a gestão do território, seguindo o tema do evento.

\section{Resultados}

Com essas ações foram alcançados um público de aproximadamente 500 pessoas (FIGURA 2). Faz-se relevante discutir o papel de divulgação da RPPN Estadual MO'Ã, como um espaço que futuramente os alunos destas escolas e as demais da região, poderão visitar e nos eventos acadêmicos possibilitar vínculos que proporcionem pesquisas para a conservação de áreas protegidas. Desta forma estas palestras foram importantes para o conhecimento dessas entidades da existência de uma UC e também conhecer a Fundação MO'Ã como um ONG que atua na região central do estado do Rio Grande do Sul.

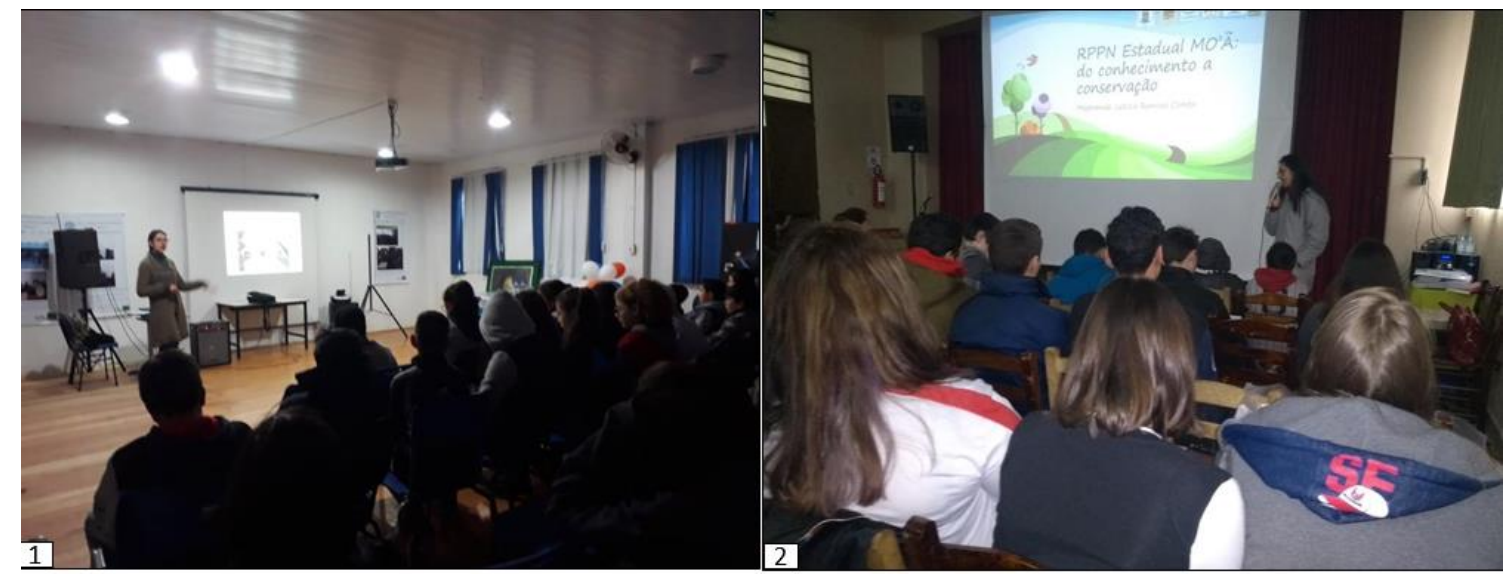

Figura 2: Palestras realizadas nas escolas. 1)Palestra na Escola Alfredo Lenhadt. 2) Palestra na Escola Pão dos pobres.

Figure 2: Lectures held in schools. 1) Lecture at the Alfredo Lenhadt School. 2) Lecture in the School Bread of the poor.

Fonte: Autores, 2018/2019.

Source: Authors, 2018/2019.

$\mathrm{Na}$ escola Alfredo Lenhardt foram realizadas duas palestras ao longo de dois anos, uma na Conferência do Meio Ambiente em 2017 e outra em 2018, e estiveram presentes 250 alunos. O tema dass palestra teve como foco a divulgação da RPPN e sua relevância na região central do estado e aspectos dos recursos hídricos também foram salientados durante as palestras sendo que Itaara, é um município caracterizados por estar em um divisor de águas de duas bacias hidrográficas, a do Ibicui-mirim e do Vacacaí-mirim, e é conhecida por ser a cidade dos balneários. Desta forma foi possível abordar o tema da água a partir de imagens das drenagens que permeiam a RPPN, contextualizando-a dentro da Bacia do Arroio Manoel Alves, que abastece grande parte da população urbana do município. Durante essas 
palestras os alunos se mostraram curiosos em saber quem era e como atuava a Fundação MO'Ã, e questionaram sobre a possibilidade de visitar esta área da RPPN.

Antes da palestra os alunos foram questionados sobre a existência de UC na região. Respondendo que não sabiam da existência e que não sabiam o que correspondia uma UC. Diante disso a palestra teve como objetivo iniciar um processo de envolvimento entre as escolas e a RPPN, buscando criar laços entre de identidade com o local, valorizando a conservação da natureza.

Já na palestra realizada na Escola Pão dos Pobres e na Escola Maria Rocha, abordou-se temas como Reserva da Biosfera da Mata Atlântica e a RPPN como Zona Núcleo, sendo importante para a conservação e como espaço para sensibilização e também pesquisas ambientais. foram abordados através de imagens da área, onde observou-se o interesse dos alunos em conhecer a área, através de inúmeros questionamentos, inclusive o interesse de alunos em realizar trabalho voluntário através da Fundação MO'Ã.

Durante as palestras percebeu-se uma grande preocupação dos alunos com a questão do desmatamento e com o lixo nas ruas, e com isso destacaram a importância do poder público em agir junto as escolas na mudança de atitude das pessoas. Para isso verificou-se através da dinâmica "chuva de palavras", onde ao final de cada palestra os alunos definiam em uma palavra o que percebiam da palestra. Após o recolhimento das palavras organizou-se uma nuvem de palavras (FIGURA 3) para observar quais as palavras foram mais citadas pelos alunos.

Observou-se que a palavra "calma", "água", "pedra", "paz" se sobressaem das demais, o que remete a busca e a satisfação dos alunos em ambientes naturais. Compreende-se que a partir destas definições feitas pelos alunos do grupo, infere que buscam satisfação pessoal ao visitar áreas naturais. $E$ também a compreensão dos processos, a fim de construir uma consciência ambiental a partir do conhecimento.

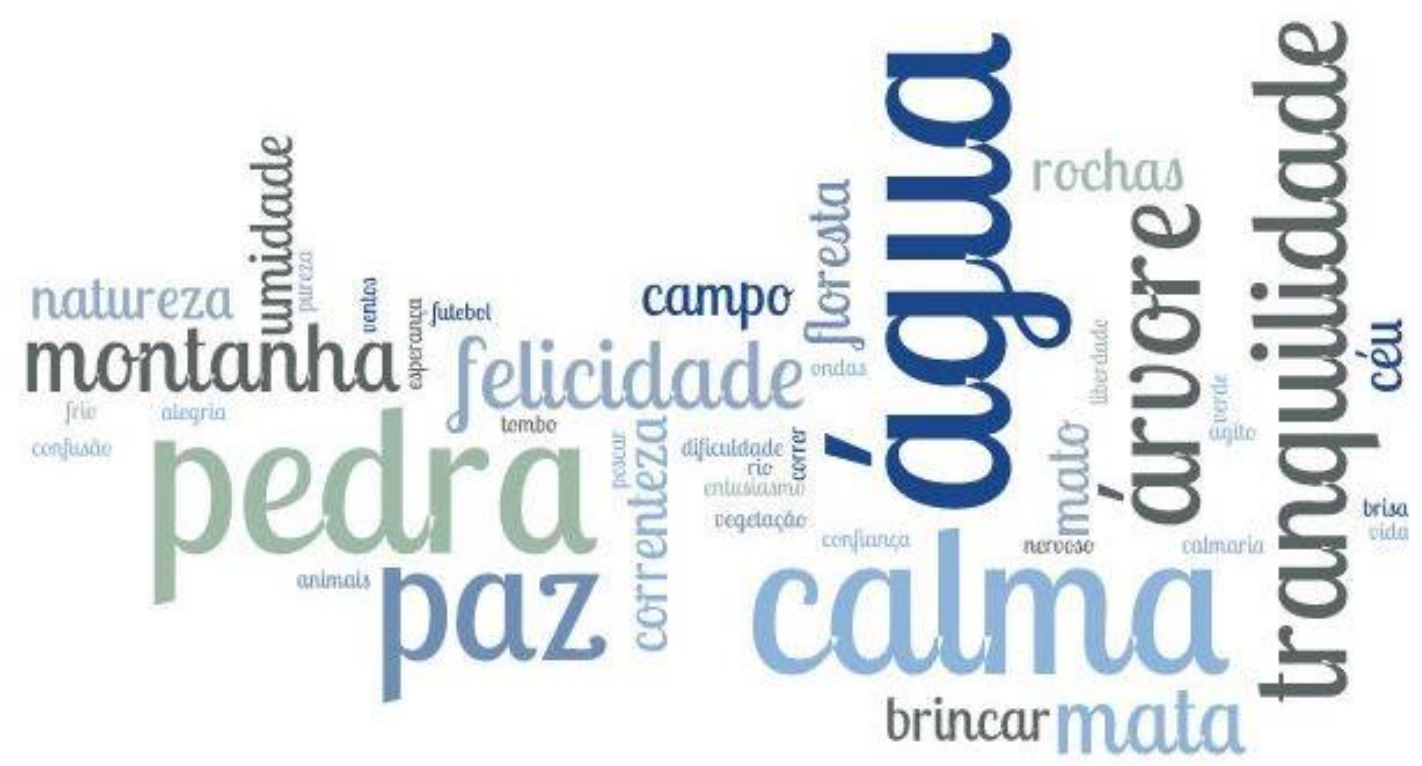

Figura 3: Nuvem de palavras formada a partir da percepção dos alunos após as palestras. Figure 3: Word cloud formed from the students' perception after the lectures. 
Para Danish et al. (1996) este período da pré-adolescência é propício para a desconstrução e reconstrução de novos pensamentos sobre diversos temas, necessitam de rejeitar ou modificar papéis anteriormente adquiridos. Por isso é relevante abordar este grupo de alunos que já possui um interesse na temática ambiental, pois estão em uma faixa etária onde já possuem capacidade de compreender os processos da natureza e a partir disso sensibilizar-se para a conservação.

$\mathrm{Na}$ perspectiva de sensibilizar através das experiências de contato direto com a natureza para promover transformações no âmbito da percepção ambiental e de certa forma que reflita nas ações da vida (MENDONÇA, 2007; WALS, 1999), e na relação com o ambiente, que este programa buscou articular subtemas complementam-se através das experiências propostas.

Durante o IV Encontro de Gestão do Território e Proteção Ambiental realizado no Laboratório da Paisagem, em Guimarães (Portugal) foi ministrada uma palestra que divulgou o Patrimônio Natural da RPPN Estadual MO'Ã e a importância da área para a conservação e gestão do território. Assim como a palestra ministrada para os cursos de licenciatura em Geografia e Planeamento e licenciatura em Proteção Civil e Gestão do território da Universidade do Minho (Portugal).

Nesse sentido Tilbury (1995) afirma que a abordagem educacional deve conduzir para uma sensibilização que só acontecerá efetivamente quando tal abordagem dar uma visão sistêmica da dinâmica ecológica, envolvendo processo da compreensão educativa, interagindo com o envolvimento dos sujeitos, que por meio das responsabilidades, buscarão a ação e participação para a solução dos problemas ambientais diagnosticados.

Após a palestra, pode-se dizer que há uma demanda por parte das escolas para que houvesse uma elaboração de um calendário ambiental com visitas periódicas à RPPN, no sentido de haver uma maior interação multidisciplinar, ação que iniciou após o processo de sensibilização propiciado pela divulgação junto as escolas.

Diante disso Sauvé et al. (2000) associaram diferentes abordagens e estratégias pedagógicas às representações que os indivíduos ou grupos sociais têm e aos objetivos e características que atribuem ao trabalho em educação ambiental. Se o ambiente é representado pela natureza que devemos apreciar e respeitar, as estratégias educacionais deverão incluir atividades de imersão na natureza como trilhas interpretativas, vivências no ambiente natural, entre outras. Nesse sentido que a RPPN Estadual MO'Ã, vem ao encontro como um espaço para o desenvolvimento dessas atividades de sensibilização. 


\section{Conclusões}

Os resultados obtidos através da pesquisa mostram que é necessário motivar estes alunos, para que possam tornar-se atores sociais ativos em suas comunidades, pois já demonstram interesse em proteger o meio ambiente.

Percebeu-se, a partir da pesquisa, a necessidade de haver projetos implantados nas escolas que não somente sensibilizem os alunos para as questões relacionadas á conservação da natureza, como também os informem sobre as características do ambiente natural e social no qual as suas escolas estão inseridas, necessidade esta explicitada pelos próprios alunos, quando falam da ausência de espaços que possam ter contato direto com a natureza. Porém, precedendo qualquer desses projetos dentro das Escolas, será necessária uma maior divulgação de informações sobre a RPPN Estadual MO'Ã junto as escolas da região central.

Salientamos a necessidades de divulgação junto a comunidade acadêmica, afim de construir vínculos institucionais para a pesquisa que contribua para a conservação e/ou proteção das Áreas Protegidas/Unidades de Conservação

\section{Referencias}

BRASIL. Decreto n. 34.256, de 02 de abril de 1992. Cria o Sistema Estadual de Unidades de Conservação e dá outras providências. Diário oficial do Estado. Porto Alegre, RS, 02 de abril de 1992. Disponível em $<$ http://www.sema.rs.gov.br/conteudo.asp?cod agrupador=12>. Acesso em 18 de Nov. de 2017.

BRASIL. Lei n. 9.985 de 18 de julho de 2000, que regulamenta o art. 225, $\S 1^{\circ}$, inciso I, II, III e VII da Constituição Federal, instituiu o Sistema Nacional de Unidades de Conservação da Natureza e dá outras providências. Presidência da República Casa Civil, Brasília, DF, 18 jul. 2000. Disponível em: <http://www.planalto.gov.br/ccivil 03/leis/l9985.htm>. Acesso em: 20 abr. 2017.

BENSUSAN,N. Conservação da biodiversidade em áreas protegidas. Rio de Janeiro: Editora FGV,2006.

CHAMI, L.; DEON, M.; SILVA, G.P. RPPN MO’Ã: Meios físico e biótipo. Estudo técnico.

$<$ http://www.sema.rs.gov.br/upload/Estudo\%20T\%C3\%A9cnico.pdf>. Acesso em 06 de Julho de 2018.

CORRÊA, L.R.; FIGUEIRÓ, A.S. Proposta de uma trilha interpretativa na Reserva Particular do Patrimônio Natural Estadual Mo'ã, Itaara (RS). Revista Brasileira de Ecoturismo, São Paulo, v.10, n.3, ago/out 2017, pp.628-644.

DANISH, S. J; NELLEN, V. C; OWENS, S. S. Teaching life skills through sport: Community-based programs for adolescents. In: VAN RAALTE, J. L.; BREWER, B. (Eds.), Exploring Sport and Exercise Psychology. Washington, DC: American Psychological Association, pp. 205-225, 1996.

DIEGUES, A. C. O Mito Moderno da Natureza Intocada. $4^{\underline{a}}$ ed. São Paulo: Editora Hucitec, 2002. 176 p. 
DOUROJEANNI, M.J.; PÁDUA, M.T. J. Biodiversidade. A hora decisiva. Curitiba: Editora da UFPR, 2007.

FERRARESE, M.D. Floristica de uma Reserva Particular do Patrimônio Natural em fragmento de Mata Atlântica(Itaara,RS,Brasil). Dissertação (de mestrado agrobiologia) 2016, 80p.

FUNDAÇÃO MO'Ã. 2017. Pesquisa e trabalhos acadêmicos. Disponível em: $<$ http://www.fundacaomoa.org.br/pesquisas.phps. Acesso em 01 de maio de 18. Janeiro, 1997.

KORMANN, T. C.; THOMAS, B.L; NASCIMENTO, D.B.; FOLETO, E.M. Contribuição Geográfica na Criação de uma Reserva Particular do Patrimônio Natural (RPPN) em Itaara- RS. Revista Geografar, Curitiba, v. 5, n. 2, p. 13-31, jul./dez. 2010.

MARCUZZO, S.B; ARAÚJO, M.M; LONGHI, S.J. Estrutura e relações ambientais de grupos florísticos em fragmento de floresta estacional subtropical. Revista Árvore, Viçosa, v. 37, n. 2, 2013. p. 275-287.

MENDONÇA, R. Educação ambiental vivencial. In: FERRARO-JUNIOR, L.A. Encontros e caminhos: formação de educadoras(es) ambientais e coletivos educadores. Brasília: MMA, 2007. v. 2. p. 117-130.

RIO GRANDE DO SUL. Portaria n. 80, de 15 de junho de 2015. Cria a Reserva Particular do Patrimônio Natural Estadual MO'Ã e dá outras providências. Secretaria do Ambiente e Desenvolvimento Sustentável. Diário Oficial do Estado. Porto Alegre, RS. 15 jun. 2015.2 Disponível em: $<$ http://www.sema.rs.gov.br/conteudo.asp?cod menu=218\&cod conteudo=9207>. Acesso em: 25 set. 2018.

SAUVÉ, L.: SATO, M. La educación ambiental: una relación constructiva entre la escuela y la comunidad. EDAMAZ e EDAMAZ. 2000.

SICK, H. (1997) Ornitologia brasileira. Rio de Janeiro: Ed. Nova Fronteira, 862p.

THOMAS,B.L; NASCIMENTO, D.B.; KORMANN, T.C. ;FOLETO, E.M. Criando uma Unidade de Conservação municipal:o caso da Reserva Particular do Patrimônio Natural da Fundação MO'Ã em Itaara,RS. Anais do XVI Encontro Nacional de Geógrafos. Porto Alegre,2010.

TILBURY, D. Environmental education for sustainability: defining the new focus os environmental education in the 1990s. Environmental Education Research, v.1, n.2, pp.195-212, UQÀM, Montreal, Canadá, 1995,167pp.

\section{Notas}

${ }^{1} \mathrm{~A}$ Reserva da Biosfera trata-se de um modelo de proteção adotado internacionalmente, visando à gestão integrada, participativa e sustentável dos recursos naturais, buscando a preservação da diversidade biológica, o incentivo ao desenvolvimento de pesquisas, o monitoramento e educação ambiental e a melhoria da qualidade de vida da população (BRASIL, 2000). No Brasil, o bioma da Mata Atlântica obteve reconhecimento como Reserva da Biosfera entre os anos de 1992 e 1993, abrangendo parte de 14 estados brasileiros, entre esses o Rio Grande do Sul. 
${ }^{2}$ Grande volume de água que escorre durante chuvas fortes e/ou prolongadas. As enxurradas ocorrem quando o solo não consegue absorver a água da chuva. (DICIONÁRIO LIVRE DE GEOCIENCIAS,2013)

3 Uma espécie é considerada Criticamente em Perigo quando as melhores evidências disponíveis indicam que se cumpre qualquer um dos critérios: Redução da população e Análise quantitativa de risco de extinção, e por isso considera-se que está enfrentando um risco extremamente alto de extinção na natureza

Letícia Ramires Corrêa: Universidade Federal de Santa Maria, Santa Maria, RS, Brasil.

E-mail: leticiarcorrea@gmail.com

Link para o currículo Lattes: http://lattes.cnpq.br/3357786530501748

Tuane Telles Rodrigues: Universidade Federal de Santa Maria, Santa Maria, RS, Brasil.

E-mail: tuanytel@hotmail.com

Link para o currículo Lattes: http://lattes.cnpq.br/5487178721406774

Data de submissão: 11 de julho de 2019

Data de recebimento de correções: 18 de dezembro de 2020

Data do aceite: 18 de dezembro de 2020

Avaliado anonimamente 